\title{
A high energy output and low onset temperature nanothermite based on three-dimensional ordered macroporous nano- $\mathrm{NiFe}_{2} \mathrm{O}_{4}$
}

Liming Shi, ${ }^{a}$ Wenchao Zhang, ${ }^{* a}$ Jia Cheng, ${ }^{a}$ Chunpei Yu, ${ }^{a}$ Ruiqi Shen, ${ }^{a}$ Jiahai Ye, ${ }^{a}$

Zhichun Qin ${ }^{\mathrm{a}}$ and Yimin Chao*b

${ }^{a}$ School of Chemical Engineering, Nanjing University of Science and Technology, Nanjing 210094, China

${ }^{\mathrm{b}}$ School of Chemistry, University of East Anglia, Norwich NR4 7TJ, UK

*Corresponding authors:

zhangwenchao303@aliyun.com

Y.Chao@uea.ac.uk

\section{ABSTRACT:}

Three-dimensional ordered macroporous (3DOM) Al/ $\mathrm{NiFe}_{2} \mathrm{O}_{4}$ nanothermite has been obtained by colloidal crystal templating method combined with magnetron sputtering processing. Owing to the superior material properties and unique 3DOM structural characteristics of composite metal oxides, the heat output of the $\mathrm{Al} / \mathrm{NiFe}_{2} \mathrm{O}_{4}$ nanothermite is up to $2921.7 \mathrm{~J} \mathrm{~g}^{-1}$, which is more than the values of $\mathrm{Al} / \mathrm{NiO}$ and $\mathrm{Al} / \mathrm{Fe}_{2} \mathrm{O}_{3}$ nanothermites in literature. More importantly, by comparison to the other two nanothermites, the onset temperature of about $300{ }^{\circ} \mathrm{C}$ from $\mathrm{Al} / \mathrm{NiFe}_{2} \mathrm{O}_{4}$ is remarkably low, which means it can be ignited more easily. Laser ignition experiment indicate that the synthesized $\mathrm{Al} / \mathrm{NiFe}_{2} \mathrm{O}_{4}$ nanothermite can be easily ignited by laser. In addition, the preparation process is highly compatible with the MEMS technology. These exciting achievements have great potential to expand the scope of nanothermite applications.

Keywords: three-dimensional ordered macroporous structural, nanothermites, $\mathrm{NiFe}_{2} \mathrm{O}_{4}$, composite materials, thermal properties 


\section{Introduction}

Energetic thermites, a class of mixture or compound that contain fuel metal and matching oxide, have been used in wide range of applications because of their high heat quantity ${ }^{1,2}$. At present, the research of nanometer scale thermites has become mainstream owning to higher-energy output and faster energy release rate compared with traditional thermite materials ${ }^{3}$. Some processes to prepare nanocomposites have been reported in literature: electrophoretic deposition ${ }^{4}$, selfassemble ${ }^{5}$, sol-gel ${ }^{6}$, and multilayered foils ${ }^{7}$. However, in the vast majority of reported nanothemites, the metal oxides are single metal oxide. High onset temperature is still a problem for the similar systems, which is leading to the difficulty of ignition with limited application in MEMS initiating explosive devices. For example, the onset temperature of $\mathrm{Al} / \mathrm{CuO}, \mathrm{Al} / \mathrm{Fe}_{2} \mathrm{O}_{3}, \mathrm{Al} / \mathrm{NiO}$ nanothermite reaction is $500{ }^{\circ} \mathrm{C}, 550{ }^{\circ} \mathrm{C}, 400{ }^{\circ} \mathrm{C}$, respectively ${ }^{8-10}$. Recent studies have indicated that the composite metal oxides (combination of two or more metals in an oxide matrix) possess unique properties, such as synergistic effect, catalytic property and electronic properties ${ }^{11}$. This can bring a superior performance in energetic material applications $^{12}$. In addition, composite metal oxides can meet with the demand of the reaction of energetic materials that require oxygen in self-sustaining reaction. In literature, sol-gel ${ }^{13}$ and the hydrothermal method ${ }^{14}$ have been employed to create the nano-composite metal oxides. However, the poor dispersion is the common disadvantage of this kind. Three-dimensionally ordered macroporous (3DOM) structure with pores sized in the sub-micrometer range is a viable alternative to solve 
dispersion problem because of the stable porous structures and uniform pore size ${ }^{15}$ 16.

In the present work, Ni-Fe composite metal oxide has been chosen to explore the possibility of the utilization in nanothemites owing to the high theoretical calorific value. The synthesized nanothermite with compound metal oxide has shown significant performance compared with traditional thermite materials, such as lower onset temperature, higher-energy output, and fully compatible with MEMS technology. It is expected that composite metal oxides are to be the focus of nanothemite studies because of their unique performance.

\section{Experimental section}

\subsection{Sample preparation:}

All purchased chemicals were of analytical grade and used without further purification. The highly monodispersed polystyrene (PS) microspheres were successfully prepared via emulsifier-free polymerization method. Subsequently the colloidal crystal template was assembled onto as-cleaned microslide substrate by depositing the suspension. The certain amount of $\mathrm{Fe}\left(\mathrm{NO}_{3}\right)_{3} \bullet 9 \mathrm{H}_{2} \mathrm{O}$ and $\mathrm{Ni}\left(\mathrm{NO}_{3}\right)_{2} \bullet 6 \mathrm{H}_{2} \mathrm{O}$ were dissolved into mixed solution of methanol and ethylene glycol (1:1 in volume) under stirring for $4 \mathrm{~h}$. Afterwards, the colloidal crystal template was immersed vertically into the resulting precursor for $5 \mathrm{~min}$, followed by drying at $50{ }^{\circ} \mathrm{C}$ for $2 \mathrm{~h}$. This process was repeated once more to let the precursor completely fill into the close-packed PS colloidal crystal. The as-fabricated samples were then pyrolyzed at $500{ }^{\circ} \mathrm{C}$ for $5 \mathrm{~h}$. The $3 \mathrm{DOM} \mathrm{NiFe} \mathrm{O}_{4}$ skeleton was formed during calcination process. 
Finally, nano-Al was deposited onto the $3 \mathrm{DOM} \mathrm{NiFe}{ }_{2} \mathrm{O}_{4}$ by magnetron sputtering under a vacuum level of $5 \times 10^{-3} \mathrm{~Pa}$ and a temperature at $30{ }^{\circ} \mathrm{C}$ in order to obtain $3 \mathrm{DOM} \mathrm{Al} / \mathrm{NiFe}_{2} \mathrm{O}_{4}$ nanothermite membrane on the substrate.

\subsection{Characterization:}

The crystal structures of all the samples were analyzed by powder X-ray diffractometer (XRD, Bruker, D8 Advance). The morphology was characterized using a field emission scanning electron microscope (SEM, Hitachi, S4800). And the differential scanning calorimetry (DSC, Mettler Toledo, DSC 1) measurement was carried out to obtain the thermodynamic performance. A pulsed laser (Beamtech, DAWA-350) was used to investigate the ignition performance of the 3DOM $\mathrm{NiFe}_{2} \mathrm{O}_{4} / \mathrm{Al}$ nanothermite membrane. The combustion behavior of sample was recorded by using a high-speed camera (HG-100K Motionxtra, Redlake MASD Inc., USA)

\section{Results and discussion}

Fig. 1 shows the $\mathrm{X}$-ray diffraction (XRD) patterns of $\mathrm{NiFe}_{2} \mathrm{O}_{4}$ membrane, $\mathrm{Al} / \mathrm{NiFe}_{2} \mathrm{O}_{4}$ membrane and the final product of $\mathrm{Al} / \mathrm{NiFe}_{2} \mathrm{O}_{4}$ membrane after a DSC test. Fig. 1 (a) is completely indexed to be $\mathrm{NiFe}_{2} \mathrm{O}_{4}$ (JCPDS NO.10-0325). Compared with Fig. 1(a), four extra peaks are observed in Fig. 1(b) and these peaks are completely indexed to Al (JCPDS No.4-787), indicating the $\mathrm{Al}$ has been deposited onto $\mathrm{NiFe}_{2} \mathrm{O}_{4}$. The results are confirmed by EDS (in Fig. 2). The peaks of $\mathrm{Ni}$, Fe and Ni, Fe, Al are observed in Fig. 2(a) and Fig. 2(b), respectively. EDS analysis also shows the atom ratio of $\mathrm{Al}, \mathrm{Fe}$ and $\mathrm{Ni}$ is 6.85:1.92:0.85 (see Table S1 in the Supporting Information). The molar ratio of Al and 
NiFe2O4 is $6.85: 0.96$. Fig. 1 (c) is the XRD pattern from the product of $\mathrm{Al} / \mathrm{NiFe}_{2} \mathrm{O}_{4}$ membrane after a DSC test. From the pattern, in the complex product, [Fe Ni] alloy (JCPD NO.18-0877) and $\mathrm{Al}_{2} \mathrm{O}_{3}$ (JCPD NO.10-0173) are the main components.

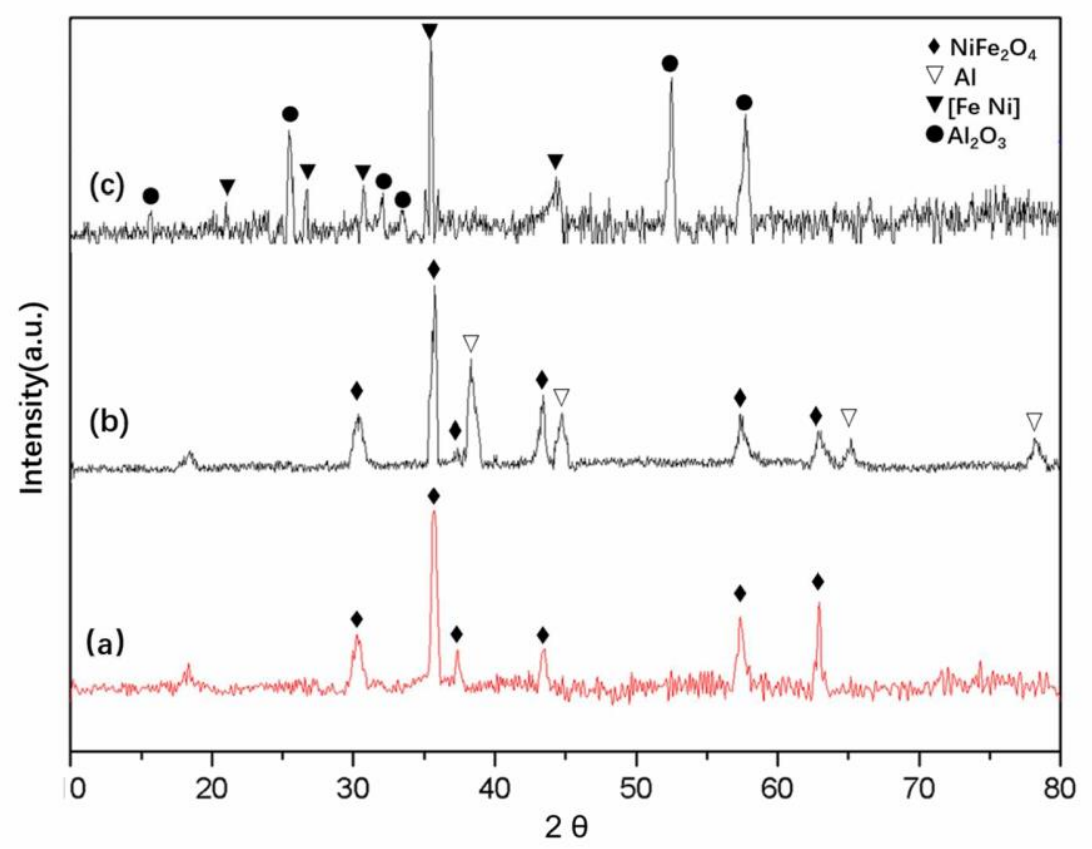

Fig. 1. XRD patterns of (a) $\mathrm{NiFe}_{2} \mathrm{O}_{4}$ membrane after calcination, (b) $\mathrm{Al} / \mathrm{NiFe}_{2} \mathrm{O}_{4}$ membrane, (c) $\mathrm{Al} / \mathrm{NiFe}_{2} \mathrm{O}_{4}$ membrane after a DSC test
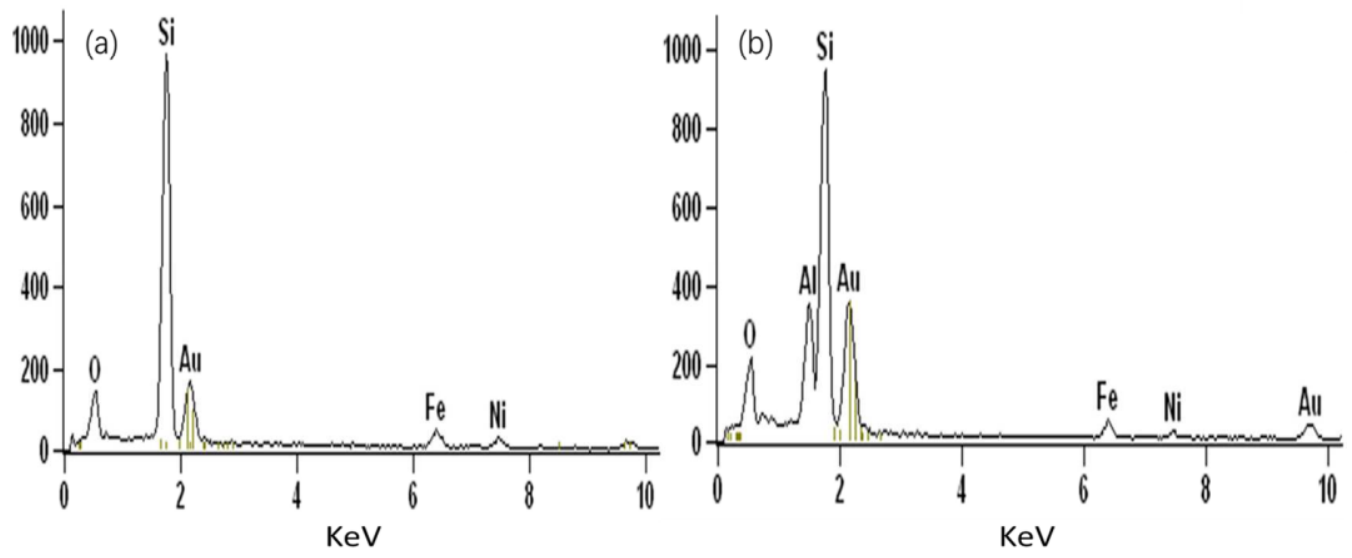

Fig. 2. EDS patterns of (a) $\mathrm{NiFe}_{2} \mathrm{O}_{4}$ membrane and (b) $\mathrm{Al} / \mathrm{NiFe}_{2} \mathrm{O}_{4}$ membrane

The morphologies of all the samples were examined by SEM. All the results are 
given in Fig. 3. The surface view, in Fig. 3(a), of the PS template shows that the particle diameter of PS particle is about $300 \mathrm{~nm}$ and every sphere is surrounded by six others. High dimensional consistency and closely packed are its main characteristic. Cross-section view in Fig. $3(\mathrm{~b})$ indicates that the thickness of PS film is about $2.8 \mu \mathrm{m}$. The $\mathrm{NiFe}_{2} \mathrm{O}_{4}$ membrane was prepared after calcination process. Fig. 3(c) shows that the $\mathrm{NiFe}_{2} \mathrm{O}_{4}$ membrane has a honeycomb structure. The size of the pore and the wall thickness are about $182 \mathrm{~nm}$ and $27 \mathrm{~nm}$, respectively. From Fig. 3(d), it can be seen that the thickness of $\mathrm{NiFe}_{2} \mathrm{O}_{4}$ membrane is about $1.5 \mu \mathrm{m}$. The changing of aperture size and thickness is mainly caused by the deformation of the PS template in the process of calcination. After the Al deposition, as shown in Fig. 3(e, f), the $\mathrm{NiFe}_{2} \mathrm{O}_{4}$ have been obviously coated by Al to form dense coalition.

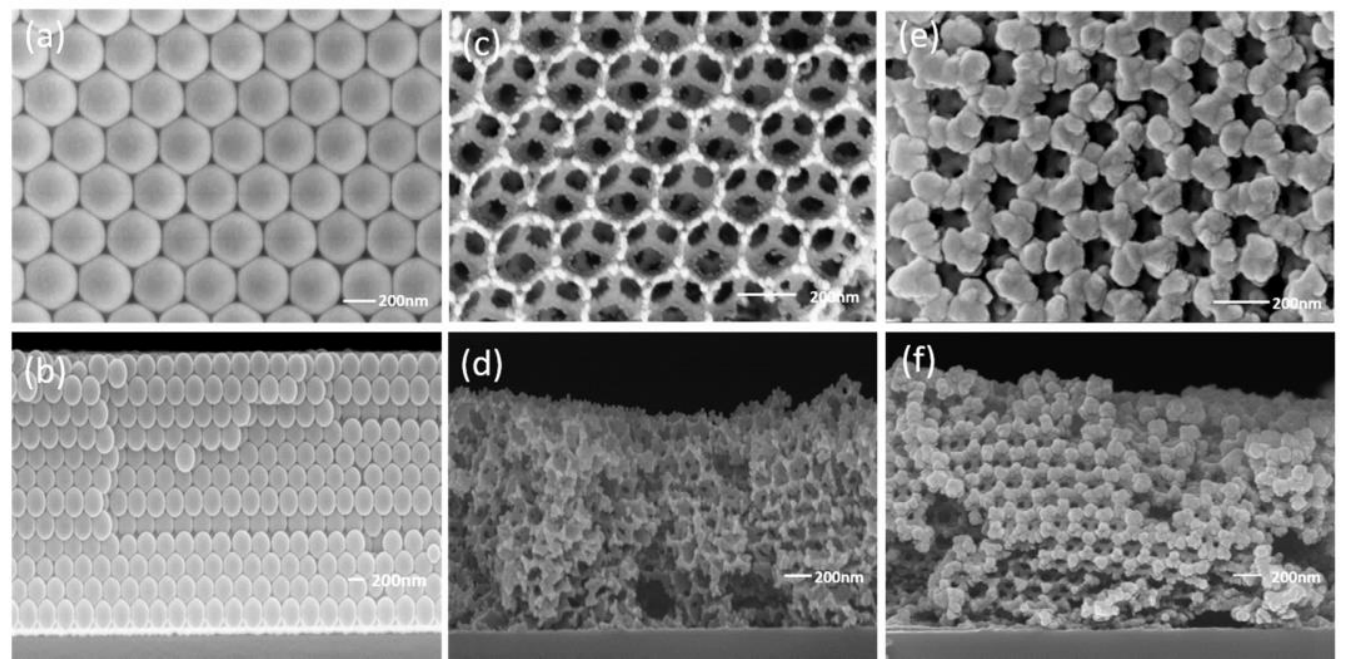

Fig. 3. SEM images of $(a, b)$ polystyrene spheres template, (c, d) 3DOM NiFe $\mathrm{O}_{4}$ membrane, and (e, f) 3DOM Al / $\mathrm{NiFe}_{2} \mathrm{O}_{4}$ membrane after Al deposition, $(a, c, e)$ surface view and $(b, d, f)$ cross-section view

Heat release and onset temperature are the main indicators of evaluating thermite.

The thermal property of the $\mathrm{Al} / \mathrm{NiFe}_{2} \mathrm{O}_{4}$ nanothermite was evaluated by $\mathrm{DSC}$ in the temperature range from 100 to $800^{\circ} \mathrm{C}$. As shown in Fig. 4, two exothermic peaks and 
one small endothermic peak in the DSC curve can be observed. At $359.2{ }^{\circ} \mathrm{C}$ and 594.6 ${ }^{\circ} \mathrm{C}$, the first and second exothermic peaks are observed, respectively. Through integral calculation of the two exothermic peak areas, from 298.2 to $464.3^{\circ} \mathrm{C}$ and 510.1 to $655.7{ }^{\circ} \mathrm{C}$, the outputs of heat are $279.4 \mathrm{~J} \mathrm{~g}^{-1}$ and $2642.3 \mathrm{~J} \mathrm{~g}^{-1}$, respectively. The total heat release is $2921.7 \mathrm{~J} \mathrm{~g}^{-1}$. The value is more than that from Al/NiO (2200 J $\mathrm{g}^{-1}$ ) and $\mathrm{Al} / \mathrm{Fe}_{2} \mathrm{O}_{3}\left(2830 \mathrm{~J} \mathrm{~g}^{-1}\right)$, which have been reported before ${ }^{10,16}$. High heat release is due to two factors. First, unique three-dimensional reticular structure greatly increases the oxide surface area in contact with the fuel, conducive to the full response. Second, calcination treatment of oxide and magnetron sputtering plating aluminum method is adopted to reduce the content of impurities such as alumina ratio. The melting of $\mathrm{Al}$ caused a small endothermic peak at $660^{\circ} \mathrm{C}$ and the very small endothermic peak indicate that $\mathrm{Al}$ has almost completely reaction. In particular, the onset temperature of $\mathrm{Al} / \mathrm{NiFe}_{2} \mathrm{O}_{4}\left(298.2{ }^{\circ} \mathrm{C}\right)$ thermite reaction is much low compared with that of $\mathrm{Al} / \mathrm{NiO}\left(400{ }^{\circ} \mathrm{C}\right)$ and $\mathrm{Al} / \mathrm{Fe}_{2} \mathrm{O}_{3}\left(550{ }^{\circ} \mathrm{C}\right){ }^{9},{ }^{10}$. Gradient experiments were done to verify the reproducibility of the phenomenon, the results were shown in Fig. 5. It shows that the initial reaction temperature is between $295-300{ }^{\circ} \mathrm{C}$. In addition, the DSC curve of pure $\mathrm{NiFe}_{2} \mathrm{O}_{4}$ (see Fig. S1 in the supporting information) shows that there is no exothermic peak near $300^{\circ} \mathrm{C}$. This means that the first slow rising heat release curve was caused by the mild react of the nanoscale $\mathrm{Al} / \mathrm{NiFe}_{2} \mathrm{O}_{4}$ membrane. It is noteworthy that the second exothermic peak occurs below the melting point of $\mathrm{Al}, 660^{\circ} \mathrm{C}$. This phenomenon is not common in the previous literature. The possible reason for the phenomenon is synergistic effect or 
catalytic property of composite metal oxide ${ }^{11}$, but the mechanism is not fully understood.

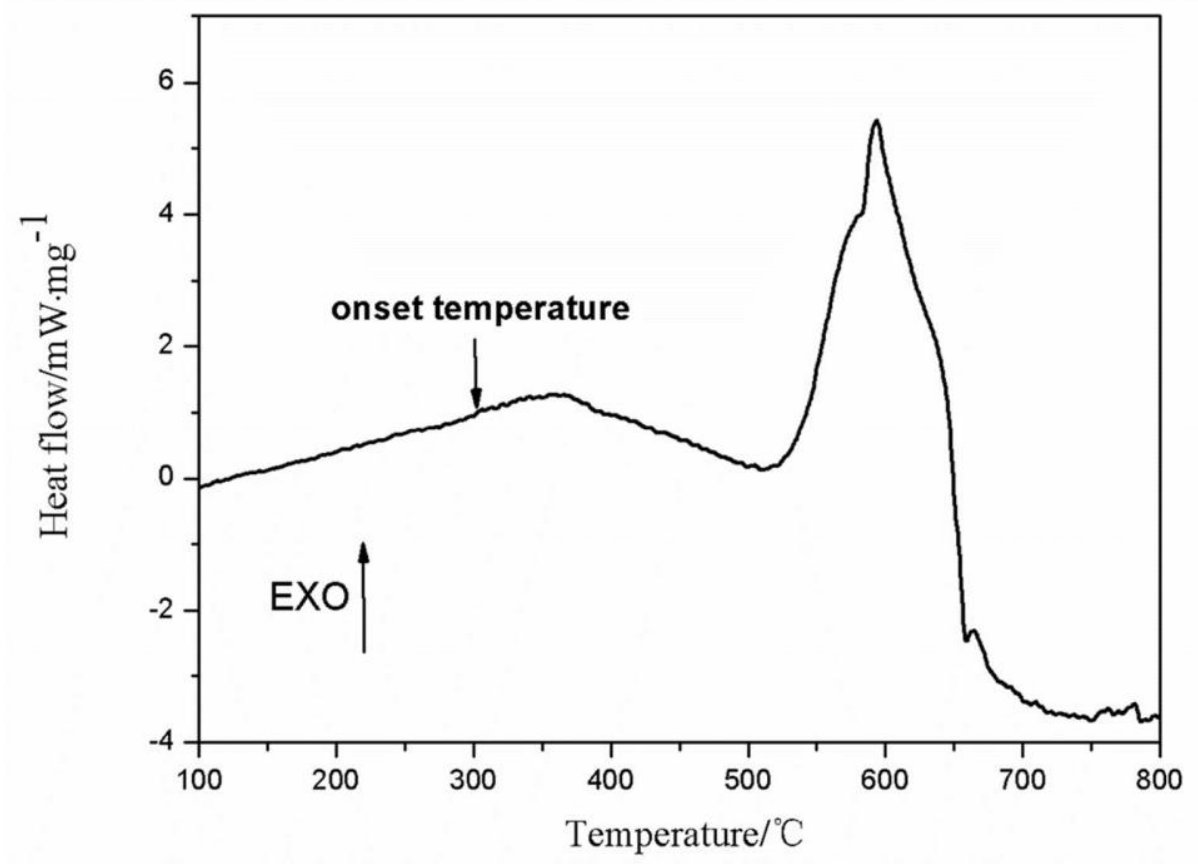

Fig. 4. $\mathrm{DSC}$ curve of $\mathrm{Al} / \mathrm{NiFe}_{2} \mathrm{O}_{4}$ membrane with an aluminizing duration of $15 \mathrm{~min}$ obtained in a temperature range from 100 to $800{ }^{\circ} \mathrm{C}$ with a heating rate of $20^{\circ} \mathrm{C} \mathrm{min}^{-1}$ under a $30.0 \mathrm{~mL} \mathrm{~min}^{-1} \mathrm{~N} 2$ flow.
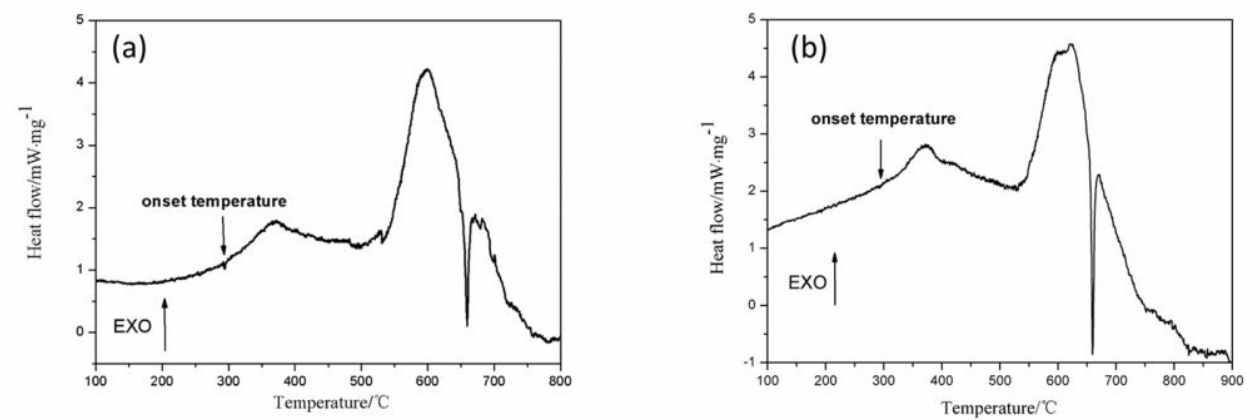

Fig. 5. DSC curve of $\mathrm{Al} / \mathrm{NiFe}_{2} \mathrm{O}_{4}$ membrane with an aluminizing duration of (a) $30 \mathrm{~min}$ and (b) $45 \mathrm{~min}$ Laser ignition experiment has been employed to further verify the ignition performance of $\mathrm{Al} / \mathrm{NiFe}_{2} \mathrm{O}_{4}$ membrane, see Fig. 6. Combustion is completed within ca. 
$99 \mu$ s and a bright flame has been observed. It is noteworthy that the incident energy is only $74 \mathrm{~mJ}$ per pulse. High burning rate, bright flame and low input energy indicate that the synthesized $\mathrm{Al} / \mathrm{NiFe}_{2} \mathrm{O}_{4}$ nanothermite can be easily ignited by laser.
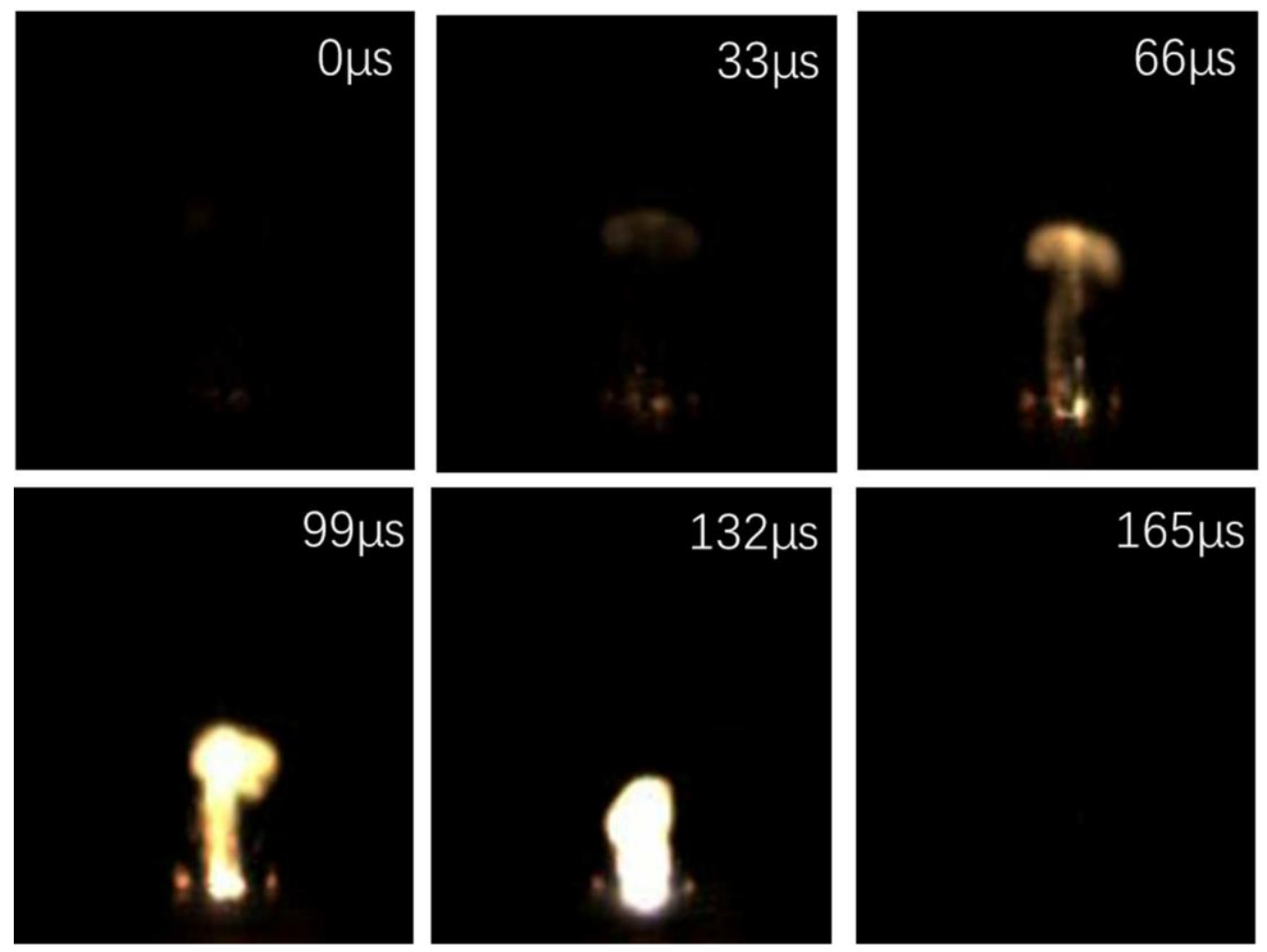

Fig. 6. Flame propagation images of $\mathrm{Al} / \mathrm{NiFe}_{2} \mathrm{O}_{4}$ membrane under the laser ignition

\section{Conclusions}

$\mathrm{NiFe}_{2} \mathrm{O}_{4}$ nanothermite has been successfully developed by unique polystyrene spheres template, with Al deposited onto it by magnetron sputtering processing. With this unique pathway, the following achievements have been verified: increased effective component, improved heat release and combustion performance of $\mathrm{Al} / \mathrm{NiFe}_{2} \mathrm{O}_{4}$ nanothermite owing to reduced impurities and alumina. Furthermore, the self-catalysis of $\mathrm{NiFe}_{2} \mathrm{O}_{4}$ has significantly contributed to a decreased onset temperature of nanothermite reaction, leading to the easy ignition of thermite. 
These characteristics are important for the nanothermite application in initiating explosive devices, especially the use in MEMS pyrotechnics that require low ignition energy and high output power.

\section{Acknowledgments}

This work was supported by National Natural Science Foundation of China (Grant 51576101), National Science Foundation of Jiangsu Province of China (Grant BK20141399), the Fundamental Research Funds for the Central Universities (Grant 30915012101).

\section{References}

1. C. Zhou, New Chemical Materials, 2010.

2. L. L. Wang, Z. A. Munir and Y. M. Maximov, Journal of Materials Science, 1993, 28, 3693-3708.

3. L. Menon, S. Patibandla, K. B. Ram, S. I. Shkuratov, D. Aurongzeb, M. Holtz, J. Berg, J. Yun and H. Temkin, Applied Physics Letters, 2004, 84, 4735.

4. D. Zhang, X. Li, B. Qin, C. Lai and X. Guo, Materials Letters, 2014, 120, 224-227.

5. R. Thiruvengadathan, C. Staley, J. M. Geeson, S. Chung, K. E. Raymond, K. Gangopadhyay and S. Gangopadhyay, Propellants, Explosives, Pyrotechnics, 2015, $40,729-734$

6. V.A. Chaudhari and G. K. Bichile, Quarterly Journal of Speech, 2015, 75, 1-24.

7. J. Y. Ahn, S. B. Kim, J. H. Kim, N. S. Jang, D. H. Kim, H. W. Lee, J. M. Kim and S. H. Kim, Journal of Micromechanics and Microengineering, 2016, 26, 015002

8. K. Zhang, C. Rossi, G. A. Ardila Rodriguez, C. Tenailleau and P. Alphonse, Applied 
Physics Letters, 2007, 91, 113117.

9. N. Zhao, C. He, J. Liu, H. Gong, T. An, H. Xu, F. Zhao, R. Hu, H. Ma and J. Zhang, Journal of Solid State Chemistry, 2014, 219, 67-73.

10. K. Zhang, C. Rossi, P. Alphonse, C. Tenailleau, S. Cayez and J.-Y. Chane-Ching, Applied Physics A, 2008, 94, 957-962.

11. Y. Wang, X. Xia, J. Zhu, Y. Li, X. Wang and X. Hu, Combustion Science \& Technology, $2011,183,154-162$.

12. D. J. Stacchiola, S. D. Senanayake, P. Liu and J. A. Rodriguez, Chemical reviews, $2013,113,4373-4390$.

13. N. Bayal, P. Jeevanandam, N. Bayal and P. Jeevanandam, Ceramics International, $2014,40,15463-15477$.

14. X. Xia, J. Tu, Y.Zhang, X. Wang, C. Gu, X. Zhao and H. J. Fan, Acs Nano, 2012, 6, 5531-5538.

15. T. Charoensuk, U. Boonyang, C. Sirisathitkul, P.Panchawirat and P. Senthongkaew, Materials Science, 2014, 20, 97-102.

16. W. Zhang, B. Yin, R. Shen, J. Ye, J. A. Thomas and Y. Chao, ACS applied materials \& interfaces, 2013, 5, 239-242. 


\section{The Table of Contents Entry}
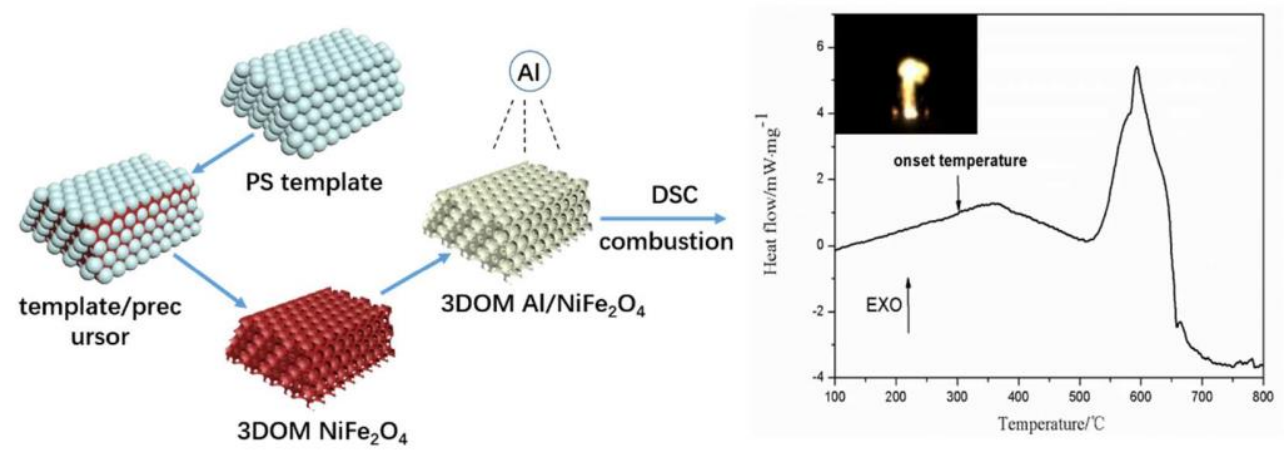

$3 \mathrm{DOM} \mathrm{Al} / \mathrm{NiFe}_{2} \mathrm{O}_{4}$ nanothermite with significantly improved higher heat output, lower onset temperature. 